\title{
混凝土过长等待时间试验验证及技术措施
}

尚徐杰

浙江省天台县台州巨錭混凝土有限公司

DOI:10.18686/bd.v2i5.1372

[摘 要] 预拌混凝土在生产、运输及浇注过程中,经常因为一些因素致使出厂坉落度偏小或等待过程中流动性经时损失过 大而引起施工困难或无法施工, 在此情况下混凝土拌合物需经二次调整才能满足施工要求。由于施工现场条件限制,调整多 为二次掺入外加剂方法来调整硂拌合物的和易性。本室在应对此问题时经过试验和生产应用对所选外加剂品种掺量经过二 次掺入法应用到硂中对硅坉落度增值、凝结时间、28 验和工程跟踪得出试验结论及技术措施。

[关健词] 预拌混凝土; 经时损失;二次调整; 技术措施

\section{1 试验原材料}

(1)水泥: 象山海螺 P.042.5 细度 $(45 \mu \mathrm{m})$ 篮余 $0.8 \%$ 比 表面积 $350 \mathrm{~cm} / \mathrm{g}$ 标准稠度用水量 $26.4 \%$, 初凝时间 130 分 钟,终凝 240 分钟, 28 天强度为 $49.0 \mathrm{Mpa}$ 。

(2)粉煤灰: 前所电厂 F 类 II 级灰, 细度 $22 \%$, 需水比 $99 \%$,抗压强度比为 $71 \%$ 。

(3) 减水剂: 浙江五龙 ZWL-II 高效葲送剂, 密度 $1.170 \mathrm{~g} / \mathrm{ml}$, 含固量 $26.8 \%$, 减水率 $20 \%$, 掺量 $1.8 \%$, 流动度 $232 \mathrm{~mm}$ 。

(4)矿粉: 台州建力 $\mathrm{S} 95$ 级密度 $2.9 \mathrm{~g} / \mathrm{cm}^{2}$ 比表面积 $407 \mathrm{~m}^{2}$ $/ \mathrm{kg}$ 流动度 $108 \%$ 。

(5)砂: 敏江 II 区中砂,级配及各项指标符合要求。

(6)石: 破碎卵石颗粒级配 5-31.5mm 及各项指标符合 要求。

\section{2 标准温度下外加剂不同掺量的试验过程}

2.1 本次试验以常用配合比为基准配比、在标准室温 （温度 $20^{\circ} \mathrm{C}$ 湿度 $65 \%$ ）密封静止状态下均落损失至 $120 \mathrm{~mm}$ 以下所需时间并通过递增法二次加人外加剂经过试拌（主 要验证二次加人外加剂时混凝土倜落度增值情况, 强度波 动情况及目测缓凝后的水泥与外加剂适用性情况, 测得表 2 相关拌合物的性能及 28 天强度。

表 1 标准温度下试验配比及外加剂掺量 \begin{tabular}{|l|l|l|l|l|l|l|l|}
\hline 水泥 $(\mathrm{KG})$ & 们粉 $(\mathrm{KG})$ & 粉煤灰 $(\mathrm{KG})$ & 砂 $(\mathrm{KG})$ & 石 $(\mathrm{KG})$ & 水 $(\mathrm{KG})$ & 外加剂 $(\mathrm{KG})$ & 掺量 $(\%)$ \\
\hline 240 & 55 & 74 & 787 & 961 & 183 & 7.38 & 2.0 \\
\hline
\end{tabular}

表 2 硂和易性、凝结时间及 28 天强度

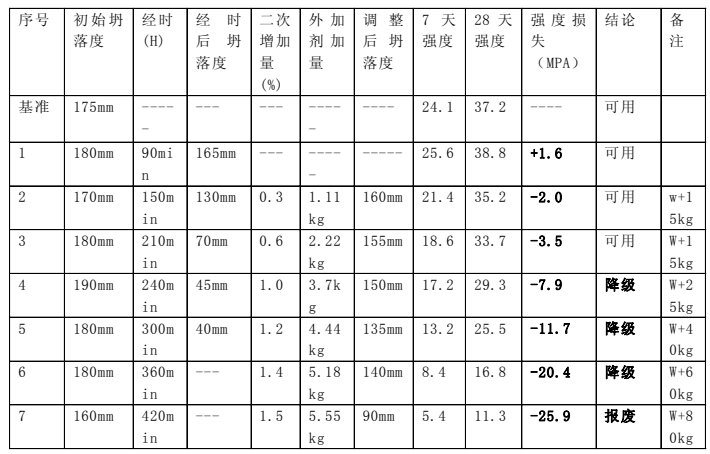

注: 为接近实际本试验所用粗细集料选用含水率为: 砂 $9 \%$ 石 $1.0 \%$

2.2 自然条件下 (夏季室外温度 $29-38^{\circ} \mathrm{C}$ ) 采用基准配 合比在经时损失情况下根据混凝土和易性能二次掺人外加 剂继续摚拌 $35 \mathrm{~S}$ 在坍落度满足施工要求下测得混凝土和易 性及同条件下物理性能见表 3 ,表 4 。

表 3 混凝土拌合物采用配合比及各个性能试验数据

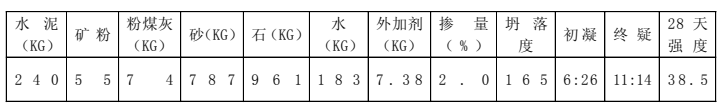

表 4 混凝土不同时段不同掺量拌合物各个性能指标

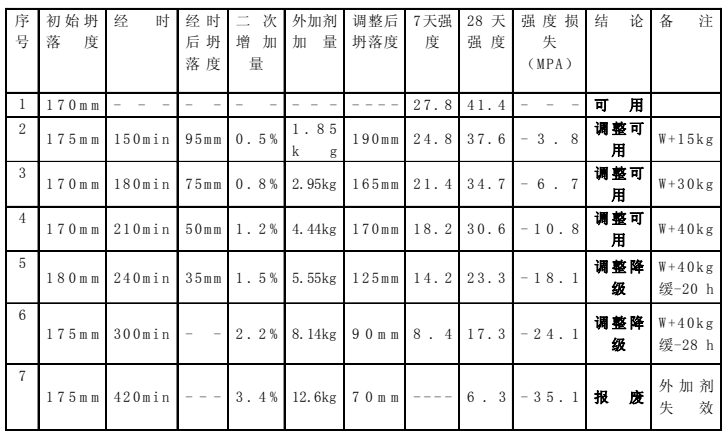

\section{3 试验结论及技术防制措施}

3.1 随着外加剂掺量增加(主要是外加剂中的缓凝成份 增加), 混凝土的凝结时间也相应延长。掺量达到一定程度后 混凝土出现超时缓凝、同时 7 天 28 天强度也随之大幅度下 降。给施工带来重大问题。特别是在经时掺加外加时此类现 象表现突出还有外加剂与水泥适用性也随之降低。所以在 生产中严格控制外加剂掺量。二次加外加剂调整混凝土的 和易性时应首先掌握配合比的基准掺量和混凝土加水摚拌 初始时间。在此掺量上根据混凝土的加水经时时间及坍落 度的损失情况适量加人外加剂, 但经时等待时间超过 4 个 小时调整二次增加外剂后必须降级使用。在 4 个小时内增 加的外加剂严禁超出基准掺量的 1.5\%, (超出后易造成混 凝土离析,严重超时缓凝, 硬化有收缩裂缝、强度下降 $50 \%$ 


\section{关于建筑基础工程建设 CFG 桩施工与质量控制的探讨}

部刚

浙江施朗龙山工程设计有限公司

DOI:10.18686/bd.v2i5.1376

[摘要] 建筑基础工程质量直接关系到建筑工程安全和稳定,并且其属于地下隐蔽工程,处理比较困难, 而且其合理处理对 于建筑工程项目建设的顺利进行非常重要,因此为了保障建筑工程的安全性,本文阐述了建筑基础工程建设存在的主要问 题以及 $\mathrm{CFG}$ 桩作用,对建筑基础工程建设中的 CFG 桩施工要点及其质量控制进行了探讨分析, 旨在保障建筑工程建设的顺 利实施。

[关键词] 建筑基础工程建设; 问题; $\mathrm{CFG}$ 桩; 作用; 施工要点; 质量控制

$\mathrm{CFG}$ 桩是指以碎石为基础,掺人一些石屑、少量水泥和 粉煤灰,加水拌合而制成的桩。建筑基础工程建设中的 CFG 桩施工工艺较为简单, 具有较高的性价比, 能够有效提高建 筑工程施工质量, 基于此, 以下就建筑基础工程建设中的 CFG 桩施工及其质量控制进行了探讨分析。

\section{1 建筑基础工程建设存在的主要问题以及 CFG 桩作} 用分析

1.1 建筑基础工程建设建设存在的问题分析

主要表现为:(1)强度及稳定性问题。基础的强度问题直 接决定了房建的质量好坏, 当基础的抗剪强度不足以支撑 上部结构的自重及外荷载时, 基础就会产生局部或整体剪 切破坏。(2)压缩及不均匀沉降问题。建筑不可避免的问题是 沉降问题,这一直是专家学者研究的课题之一。当基础在上 部结构的自重及外荷载作用下产生过大变形时, 会影响建 筑物的正常使用, 特别是超过规范所容许的不均匀沉降时, 结构可能会开裂。(3)由于动荷载引起的基础问题。当遇到不 可避免的因素,例如地震或爆破等时,这种动载荷动力会引 起基础土、特别是饱和无黏性土的液化、失稳和震陷等。

1.2 建筑基础工程建设的 CFG 桩作用

主要表现为:(1)CFG 桩的桩体作用。CFG 桩的桩体压 缩性在荷载作用下明显比其周围的软土小, 因此基础传给
复合地基的附加应力会随着地基的变形而逐渐集中到桩体 上,出现应力明显集中的现象。由于桩体承受了大部分的荷 载,使得桩间土的应力相应减小,因此软土地基的承载力比 原有地基的承载力大。此外,地基沉降量减小,伴随着 CFG 桩桩体的刚度增加,桩体的作用更加明显。(2)裖垫层的作 用。裖垫层是由散体材料组成,主要作用有: 保证桩、土能共 同承担荷载; 调整桩的垂直荷载分担; 减少基础底面应力的 集中; 调整桩、土分担水平荷载的能力。(3)排水作用。建筑基 础工程建设中 $\mathrm{CFG}$ 桩施工过程中,当采用沉管灌注施工法 时,在施工和成桩后一段时间内,会不同程度地降低地层中 的地下水含量, 改善地基土的物理力学性质。在饱和的粉 上、沙土中施工时,沉管和拔管的振动会让上体产生超孔隙 压力, 孔隙水将会沿着桩体排出, 且排出方向向上, 直到 CFG 桩体硬结为止。

\section{2 建筑基础工程建设中的 CFG 桩施工要点分析}

建筑基础工程建设中的 $\mathrm{CFG}$ 桩施工要点主要表现为: (1)CFG 桩施工准备要点分析。主要表现为:第一、材料准 备。所需材料需检测试验,选定合格的原材料产地或供应方 后, 可进行混合料的配合比试验。第二、合理选用施工机械。 桩机选用需要保证下钻能力,优先选择履带式打桩机, 保证 雨期施工,地洜需优先考虑采用柴油机的,降低施工用电,保
以上。一般常温条件下经时 4 个小时内每一方混凝土增加 $0.5 \mathrm{~kg}$ 可增大 $25-40 \mathrm{~mm}$ 坞落度, 凝结时间在温度 $20-35^{\circ} \mathrm{C}$ 间 可适当延长 40 分钟到 1.0 个小时。

\section{2 在二次加人外加剂时}

第一:应注意搅拌车搅拌时间控制在 90 秒以上防止因 搅拌不均局部掺量过大而形成超时缓凝造成质量事故。

第二：保证混凝土在调整搅拌过程中有充分摚拌空间 以避免混凝土出现和易性不均。

第三: 详细了解该混凝土的加水拌合时间确定混凝土 延长时间、目测混凝土拌合物坍落度和粘聚性在允许调整 范围内, 跟据试验结果在 3.5 小时内 (温度 $20-35^{\circ} \mathrm{C}$ ) 可在现 场适量加人外加剂调整。超出该范围应通知技术负责人退
回厂调整后降级使用。

第四: 在混凝土加水拌合调整等待时间累计超过 6:30 小时以上的可作报废处理严禁用于承重部位。

第五: 调整后混凝土必需留置试块做好质量处理记录 与不合格品处理记录以备复查。

\section{参与文献:}

[1]何建青.混凝土结构工程裂缝处理方法浅析 [J]. 四 川建筑,2016,36(05):163-165+169.

[2]邹明亮.浅析解决预拌混凝土裂缝问题措施 [J/OL]. 河南建材,2018,(02):323-325

[3]白辛.预拌混凝土裂缝成因分析及控制技术 [J]. 黑 龙江科技信息,2016,(14):268. 